\title{
Klebsiella pneumoniae Planktonic and Biofilm Reduction by Different Plant Extracts: In Vitro Study
}

\section{Lucas Paula-Ramos, Carlos Eduardo da Rocha Santos, Daphne Camargo Reis Mello, Lígia Nishiama Theodoro, Felipe Eduardo De Oliveira, Graziella N. Back Brito, Juliana Campos Junqueira, Antonio Olavo Cardoso Jorge, and Luciane Dias de Oliveira}

Department of Biosciences and Oral Diagnosis, São Paulo State University (Unesp), Institute of Science and Technology,
São José dos Campos, Francisco José Longo 777, São Dimas, 12245-000 São José dos Campos, SP, Brazil

Correspondence should be addressed to Lucas Paula-Ramos; lucas93paula@hotmail.com.br

Received 4 August 2016; Accepted 2 November 2016

Academic Editor: Carlos Henrique Gomes Martins

Copyright (C) 2016 Lucas Paula-Ramos et al. This is an open access article distributed under the Creative Commons Attribution License, which permits unrestricted use, distribution, and reproduction in any medium, provided the original work is properly cited.

\begin{abstract}
This study evaluated the action of Pfaffia paniculata K., Juglans regia L., and Rosmarius officinalis L. extracts against planktonic form and biofilm of Klebsiella pneumoniae (ATCC 4352). Minimum inhibitory concentration (MIC) and minimum microbicidal concentration (MMC) values were determined for each extract by microdilution broth method, according to Clinical and Laboratory Standards Institute. Next, antimicrobial activity of the extracts on biofilm was analyzed. For this, standardized suspension at $10^{7} \mathrm{UFC} / \mathrm{mL}$ of $\mathrm{K}$. pneumoniae was distributed into 96-well microplates $(n=10)$ and after $48 \mathrm{~h}$ at $37^{\circ} \mathrm{C}$ and biofilm was subjected to treatment for $5 \mathrm{~min}$ with the extracts at a concentration of $200 \mathrm{mg} / \mathrm{mL}$. ANOVA and Tukey tests (5\%) were used to verify statistical significant reduction $(p<0.05)$ of planktonic form and biofilm. P paniculata K., $R$. officinalis L., and J. regia L. showed reductions in biomass of 55.6, 58.1, and $18.65 \%$ and cell viability reduction of $72.4,65.1$, and $31.5 \%$, respectively. The reduction obtained with $P$. paniculata and $R$. officinalis extracts was similar to the reduction obtained with chlorhexidine digluconate $2 \%$. In conclusion, all extracts have microbicidal action on the planktonic form but only P. paniculata $\mathrm{K}$. and $R$. officinalis $\mathrm{L}$. were effective against biofilm.
\end{abstract}

\section{Introduction}

Klebsiella pneumoniae belongs to Enterobacteriaceae family and it has emerged as an important pathogen, responsible for nosocomial infections, focusing on urinary (UTIs) and respiratory tracts and blood infections. Although it is a common colonizer of skin, gastrointestinal tract, and nasopharynx, it is a risk for patients hospitalized for long periods and with compromised immune system. It is also responsible for more than $70 \%$ of infections in humans. When organized in biofilms, virulence factor that makes it an extremely resistant microorganism, it offers great resistance to the diffusion of antimicrobial drugs [1-4], with little or no treatment option being developed [5].

Due to the increasing resistance to antimicrobial drugs, especially after the 70s, when several strains emerged with a high antimicrobial resistance rate, such as cephalosporins and fluoroquinolones, new treatment options became extremely important. Thus, studies with alternative methods, such as herbal medicines, are growing as a promising field to combat resistant strains. A great number of studies tried to explain the action potential of natural extracts; however, nowadays, there are over 3000 species that have not been evaluated. Therefore, the extracts selected for this study show little or no information regarding their antimicrobial potential [6-8].

Pfaffia paniculata K. is a common root in South America, especially in Brazil, popularly known as Brazilian ginseng. It belongs to Amaranthaceae family and it is known for its anti-inflammatory potential. Studies indicate that its action potential can be much higher, even against tumor cells in different sites. However, regarding its antimicrobial activity, there is nothing so far described in the literature $[9,10]$.

Juglans regia L., which belongs to Juglandaceae family, popularly known as walnut, is a common tree in South Eastern Europe. Its fruits have high nutritional content and are rich in antioxidants. Researches around the walnut show 
anti-inflammatory, analgesic, and antimicrobial actions. Its antimicrobial activity was tested against Gram-positive and Gram-negative microorganisms and shows promising results, varying according to the type of extract $[11,12]$.

Rosmarinus officinalis L. is a shrub from the mediterranean region, drift of Lamiaceae family that has been used for medicinal purposes in the treatment of bacterial and fungal infections [13]. It presents preventive and/or curative action of diseases such as asthma, tonsillitis, nasal obstruction, and constipation. It has monoterpenes with antibacterial and antifungal potential, especially against Gram-positive bacteria [14].

Taking into consideration what has been exposed before, this study aimed to evaluate the antimicrobial action of glycolic extracts of $P$. paniculata K, J. regia L., and R. officinalis L. against $K$. pneumoniae planktonic suspension and biofilm.

\section{Materials and Methods}

Glycolic extracts of Pfaffia paniculata, Juglans regia, and Rosmarinus officinalis were purchased from Mapric company with the appropriate reports and specifications.

Klebsiella pneumoniae ATCC 4352, from Microbiology and Immunology Laboratory-Institute of Science and Technology/UNESP, was used for the evaluation of antimicrobial activity of the glycolic extracts.

\subsection{Minimum Inhibitory Concentration (MIC) and Minimum} Microbicidal Concentration (MMC). In order to determine MIC, microdilution broth method was used, according to the Clinical and Laboratory Standards Institute (CLSI), M7-A6 standard [15].

Inocula were prepared from a culture seeded on BHI agar (Brain Herth Infusion), incubated in bacteriological incubator at $37^{\circ} \mathrm{C}$ during $24 \mathrm{~h}$ in sterile physiological solution $(0,9 \% \mathrm{NaCl})$ and standardized at spectrophotometer in $10^{6}$ cells/mL, according to the recommendations of NCCLS [15].

The test was performed in 96-well microplates (TPP, Zollstrasse, Switzerland), where $100 \mu \mathrm{L}$ of Mueller Hinton (Himedia, Mumbai, India) were added and $100 \mu \mathrm{L}$ of the extract only in the first well. From the first well, 10 serial dilutions were done. Next, $100 \mu \mathrm{L}$ of microbial suspension was added into each well and the plate was incubated for $24 \mathrm{~h}$. With this method of serial dilution, concentration of each extract tested ranged from 100 to $0,19 \mathrm{mg} / \mathrm{mL}$. MIC was found in the last well of the microplate with no turbidity.

MMC of the extracts was determined by inoculating $10 \mu \mathrm{L}$ of MIC, a higher and a lower concentration into Brain Heart Infusion agar (BHI, Himedia, Mumbai, India) and the drop technique was used for seeding. After $48 \mathrm{~h}$ at $37^{\circ} \mathrm{C}$, the lowest seeded concentration that did not show growth on solid medium was determined as MMC.

2.2. Evaluation of the Antimicrobial Activity of the Extracts in Biofilms [16, 17]. The action of the extracts against Klebsiella pneumoniae monospecies biofilm was evaluated. The biofilms were formed in the bottom of 96-well plates. First, $K$. pneumoniae was suspended in Brain Hearth Infusion Broth
(Himedia) and incubated at $37^{\circ} \mathrm{C}$ during $24 \mathrm{~h}$. Next, the inoculum was washed twice with sterile saline $(0.9 \% \mathrm{NaCl})$ and standardized suspensions containing $10^{7} \mathrm{UFC} / \mathrm{mL}$ were obtained with the aid of spectrophotometer (B582, Micronal, São Paulo, Brazil). A hundred microliters of microbial suspension were placed per well in each group $(n=10)$ in 96-well microplates. The plates were incubated for $90 \mathrm{~min}$ in bacterial incubator at $37^{\circ} \mathrm{C}$ under agitation of $75 \mathrm{rpm}$ for initial adhesion. The plates were washed twice with sterile saline and $100 \mu \mathrm{L} /$ well of broth was added. Then the plates were incubated under the same conditions of initial adhesion for $48 \mathrm{~h}$, with replacement of broth after $24 \mathrm{~h}$.

2.2.1. Treatment. After, K. pneumoniae biofilm was put in contact with each extract at the concentration of $200 \mathrm{mg} / \mathrm{mL}$, separately, during 5 minutes. As a positive control, it was used $2 \%$ chlorhexidine digluconate and as a negative control $0.9 \%$ $\mathrm{NaCl}$ sterile. Subsequently, the extracts were removed and the biofilm was washed with sterile $0.9 \% \mathrm{NaCl}$.

Three independent experiments were performed, with 10 repetitions each, total $n=30$ for each group.

\subsubsection{Biofilm Measuring}

Violet Crystal. After exposure of biofilm to the extracts, $200 \mu \mathrm{L}$ of methanol was added in each well for $15 \mathrm{~min}$. The liquid was removed and the plate was incubated for $24 \mathrm{~h}$. After the incubation period, $200 \mu \mathrm{L}$ of crystal violet $1 \%(\mathrm{v} / \mathrm{v})$ was added for $5 \mathrm{~min}$. The wells were washed twice with $200 \mu \mathrm{L}$ of saline and acetic acid $33 \%(\mathrm{v} / \mathrm{v})$. The absorbance of the plates was measured in a microplate reader at a wavelength of $570 \mathrm{~nm}$. Optical density obtained was converted to reduction percentage of biofilms.

Cellular Viability. After exposure of biofilm to the extracts, $100 \mu \mathrm{L} /$ well of MTT solution (Sigma-Aldrich Co., Germany) was added and the plates were incubated, protected from light, during $1 \mathrm{~h}$ at $37^{\circ} \mathrm{C}$. Plates were washed with sterile phosphate buffered saline (PBS) (Cultilab, Brazil) and $100 \mu \mathrm{L} /$ well of dimethyl sulfoxide (DMSO, Sigma) was added. Then, the plates were incubated again, protected from light, for $10 \mathrm{~min}$ at $37^{\circ} \mathrm{C}$, under agitation for more than $10 \mathrm{~min}$. Optical densities of the wells were measured by microplate reader at a wavelength of $570 \mathrm{~nm}$, and the values obtained were converted to percentage of cell viability.

2.3. Statistical Analysis. The results were analyzed by ANOVA and Tukey test $(p<0.05)$ with Graphpad Prism 5.0 software.

\section{Results}

The results obtained with the broth microdilution test are shown in Table 1.

P. paniculata and R. officinalis showed MIC of $12.5 \mathrm{mg} / \mathrm{mL}$ and MMC of $25 \mathrm{mg} / \mathrm{mL}$. J. regia showed MIC and MMC at the same concentration of $6.25 \mathrm{mg} / \mathrm{mL}$.

Results obtained with the application of the extracts in the biofilm in the crystal violet assay are shown in Figure 1. 
TABLE 1: Broth microdilution test results with concentrations corresponding to MIC and MMC for each extract.

\begin{tabular}{lcc}
\hline & \multicolumn{2}{c}{ Klebsiella pneumoniae } \\
& MIC $(\mathrm{mg} / \mathrm{mL})$ & MMC $(\mathrm{mg} / \mathrm{mL})$ \\
\hline Pfaffia paniculata & 12,5 & 25 \\
Juglans regia & 6,25 & 6,25 \\
Rosmarinus officinalis & 12,5 & 25 \\
\hline
\end{tabular}

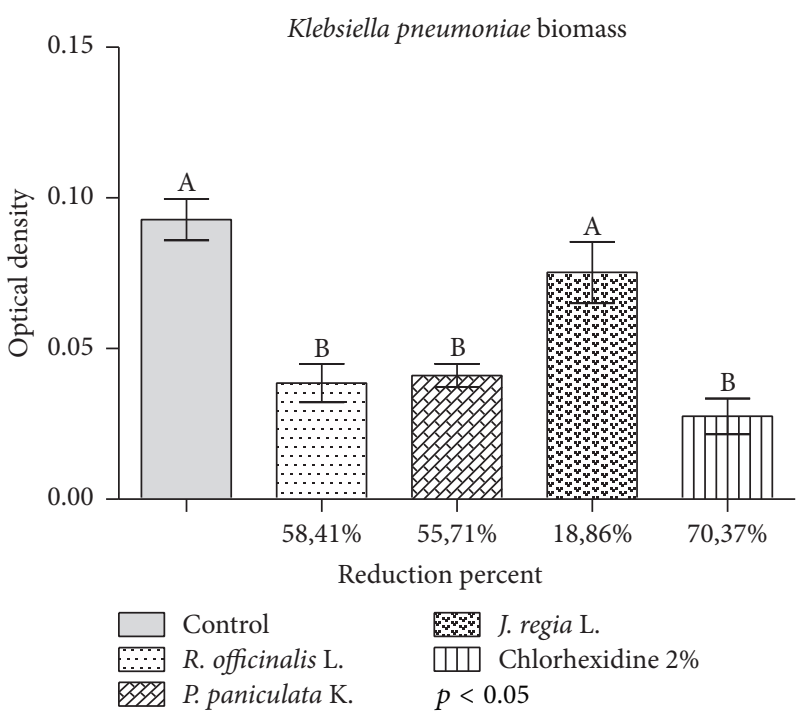

FIgURe 1: Application of glycolic extracts of $R$. officinalis, $P$ paniculata, and J. regia at concentration of $200 \mathrm{mg} / \mathrm{mL}$ in K. pneumoniae biofilm during 5 minutes. Control group was exposed to $0.9 \% \mathrm{NaCl}$ during $5 \mathrm{~min}$. The results indicate the mean values in reduction of biomass in percentage compared to the control group of each extract. Letters (A or B) express the comparison of groups in statistical analysis $(p<0.05)$.

P. paniculata and R. officinalis extracts showed statistically significant reduction when compared to the control group $(p<0.05)$. The highest mean percentages of reduction in the biofilm were $58.41 \%$ for $R$. officinalis and $55.71 \%$ for $P$. paniculata, statistically similar to $2 \%$ chlorhexidine digluconate, with reduction of $70.37 \%$.

Although $J$. regia extract has shown a mean reduction of $18.86 \%$, this was not statistically significant when compared to the control group $(p>0.05)$.

The results of cell viability test are in Figure 2.

The extracts of $R$. officinalis and $P$. paniculata showed statistically significant reduction when compared to the control group $(p<0.05)$. The mean reduction percentages in the biofilm were $72.38 \%$ for P. paniculata and $65.12 \%$ for $R$. officinalis, both statistically similar to $2 \%$ chlorhexidine digluconate, with reduction of $76.32 \%$, and $31.5 \%$ for J. regia, statistically similar to the control group.

\section{Discussion}

The results of this study demonstrated that the natural extracts have antimicrobial activity against $K$. pneumoniae, a

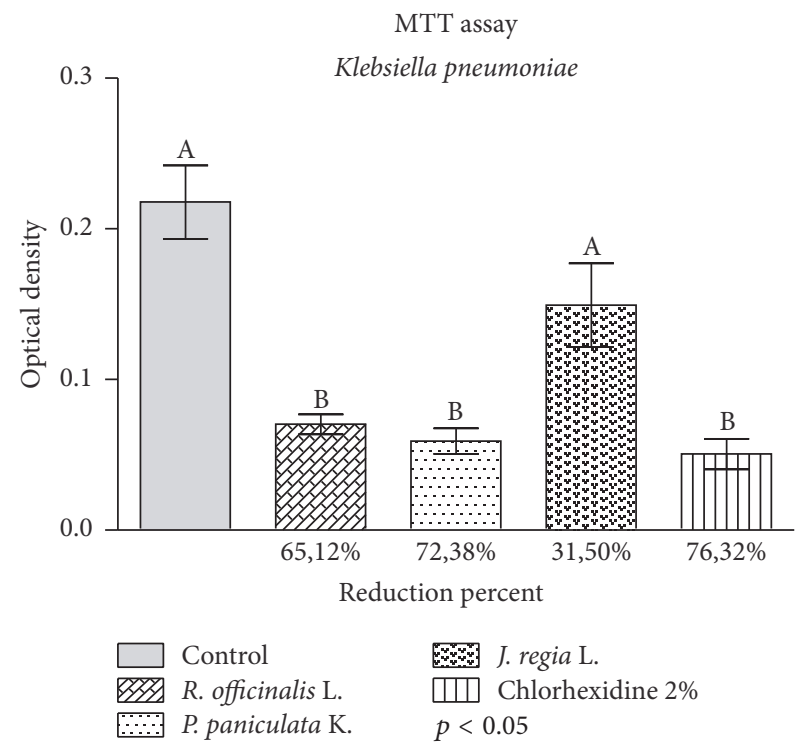

FIgUre 2: Application of glycolic extracts of $R$. officinalis, $P$ paniculata, and J. regia at concentration of $200 \mathrm{mg} / \mathrm{mL}$ against $K$. pneumoniae biofilm during $5 \mathrm{~min}$. Control group received $0.9 \%$ $\mathrm{NaCl}$ during $5 \mathrm{~min}$. The results indicate the mean values of cell viability reduction in percentage of each extract compared to the control group. Letters (A or B) express the comparison of groups in statistical analysis $(p<0.05)$.

pathogen that offers great resistance to different antibiotics [1-4]. It is remarkable that this is a pioneering study, since it checks the antimicrobial action of $P$. paniculata, J. regia, and R. officinalis glycolic extracts with lack of information in the literature [6-8].

Microbial resistance is a growing threat to global public health [18]. In the last decade, emergence of resistance to antimicrobial drugs partially reversed the advances of antibiotics that occurred during the last 80 years (National Action Plan). The high incidence of infections caused by multiresistant bacteria makes the reevaluation of treatment regimens, with alternative options, a real need for health research [19].

Pleşca et al., in a retrospective study with 178 patients with severe sepsis associated with immunosuppression frames, pointed $K$. pneumoniae as the second most common infectious agent, behind Escherichia coli. Marwa et al., in a crosssectional study with patients with and without HIV, found similar results to Pleşca et al. From clinical isolates, resistant to cotrimoxazole, a prophylactic antibiotic worldwide used against opportunistic infections, in patients with HIV or AIDS, $K$. pneumoniae appears to be the second most prevalent microorganism, behind only E. coli. These data only corroborate the importance of the results found in our study, especially regarding $R$. officinalis and $P$. paniculata extracts, that were able to significantly reduce biofilm [20, 21].

Our study has similar results to those found in the literature, according to plant or root species and type of extract tested, such as Kozłowska et al., who tested the aqueous and ethanol extracts of $R$. officinalis on standard strains of $K$. pneumoniae and they both showed inhibition on the strain ATCC 13883, but there was no inhibition on 
the strain ATCC 700603. In another research, Van Vuuren et al. tested different essential oils in combination with ciprofloxacin against different microorganisms and the best results were with $R$. officinalis essential oil associated with ciprofloxacin against K. pneumoniae NCTC 9633 [22, 23].

Pereira et al. used the aqueous extract of J. regia and found inhibition of K. pneumoniae. Abidi et al. demonstrated synergistic action of different extracts associated with antibiotics against clinical strains of Staphylococcus epidermidis, wherein the aqueous extract of J. regia was tested with several standard antibiotics such as gentamicin and vancomycin, among which cephalexin and erythromycin showed the best results. Farooqui et al. tested aqueous and methanolic extracts of J. regia on clinical and standard (ATCC) strains. Clinical strains of Gram-positive pathogens, such as Staphylococcus aureus, showed higher sensitivity to the extract; however, when tested on Gram-negative strains, the aqueous and methanolic extracts showed no significant antimicrobial activity, as well as the results obtained in our study. It is suggested that the antimicrobial action of J. regia against Gram-negative microorganisms must be strain dependent, showing greater effect on Gram-positive microorganisms. Thus, more research on Gram-positive microorganisms with different J. regia extracts could bring better results [24-26].

The results obtained with $P$. paniculata are difficult to discuss, since the articles in the literature address only their anticancer and antitumor [27, 28], anti-inflammatory [29], and cell activity modulator [30] effects, among others. However, until the present moment, there is no research with this extract regarding its antimicrobial potential, which makes our study of great importance, while opening new perspectives for studies with promising results.

Studies show that plants contain different types of monoterpenes in their composition. P. paniculata has a triterpene called pfameric acid and J. regia and $R$. officinalis have several types of monoterpenes hydrocarbons. Pham et al. reported that the monoterpene molecule has the ability to change the fluidity and the carrying of substances through the lipid bilayer. Thus, this change in the membrane permeability may have caused metabolism collapse and death of the microorganism [31-34]. The difference in susceptibility of the tested microorganism can be attributed to the rate at which the active components of the plant extracts seem to diffuse through the cell and into the phospholipids of cell membrane [35].

\section{Conclusion}

It was concluded that all glycolic extracts showed antimicrobial action against the planktonic form of $K$. pneumoniae but only $R$. officinalis and P. paniculata extracts, at $200 \mathrm{mg} / \mathrm{mL}$, showed antimicrobial action against the biofilm. These results are promising and open new avenues for research with alternative antimicrobial methods.

\section{Competing Interests}

The authors declare that there is no conflict of interests regarding the publication of this paper.

\section{References}

[1] J. D. D. Pitout, P. Nordmann, and L. Poirel, "Carbapenemaseproducing Klebsiella pneumoniae, a key pathogen set for global nosocomial dominance," Antimicrobial Agents and Chemotherapy, vol. 59, no. 10, pp. 5873-5884, 2015.

[2] L. Chen, B. Mathema, J. D. D. Pitout, F. R. DeLeo, and B. N. Kreiswirth, "Epidemic Klebsiella pneumoniae ST258 is a hybrid strain," mBio, vol. 5, no. 3, 2014.

[3] L. S. Munoz-Price, L. Poirel, R. A. Bonomo et al., "Clinical epidemiology of the global expansion of Klebsiella pneumoniae carbapenemases," The Lancet Infectious Diseases, vol. 13, no. 9, pp. 785-796, 2013.

[4] M. Pleszczyńska, A. Wiater, T. Bachanek, and J. Szczodrak, "Enzymes in therapy of biofilm-related oral diseases," Biotechnology and Applied Biochemistry, 2016.

[5] G. Benthall, R. E. Touzel, C. K. Hind et al., "Evaluation of antibiotic efficacy against infections caused by planktonic or biofilm cultures of Pseudomonas aeruginosa and Klebsiella pneumoniae in Galleria mellonella," International Journal of Antimicrobial Agents, vol. 46, no. 5, pp. 538-545, 2015.

[6] S. B. Tankeo, P. Tane, and V. Kuete, "In vitro antibacterial and antibiotic-potentiation activities of the methanol extracts from Beilschmiedia acuta, Clausena anisata, Newbouldia laevis and Polyscias fulva against multidrug-resistant Gram-negative bacteria," BMC Complementary and Alternative Medicine, vol. 15, article 412, 2015.

[7] S. A. Sargın, E. Akçicek, and S. Selvi, "An ethnobotanical study of medicinal plants used by the local people of Alaşehir (Manisa) in Turkey," Journal of Ethnopharmacology, vol. 150, no. 3, pp. 860-874, 2013.

[8] L. Karygianni, A. Al-Ahmad, A. Argyropoulou, E. Hellwig, A. C. Anderson, and A. L. Skaltsounis, "Natural antimicrobials and oral microorganisms: a systematic review on herbal interventions for the eradication of multispecies oral biofilms," Frontiers in Microbiology, vol. 6, article 1529, 2016.

[9] D. F. Felipe, L. Z. S. Brambilla, C. Porto, E. J. Pilau, and D. A. G. Cortez, "Phytochemical analysis of Pfaffia glomerata inflorescences by LC-ESI-MS/MS," Molecules, vol. 19, no. 10, pp. 15720-15734, 2014.

[10] S. M. K. Rates and G. Gosmann, "Gênero Pfaffia: aspectos químicos, farmacológicos e implicações para o seu emprego terapêutico," Revista Brasileira de Farmacognosia, vol. 12, no. 2, pp. 85-93, 2002.

[11] F. Zakavi, L. G. Hagh, A. Daraeighadikolaei, A. F. Sheikh, A. Daraeighadikolaei, and Z. L. Shooshtari, "Antibacterial effect of Juglans regia bark against oral pathologic bacteria," International Journal of Dentistry, vol. 2013, Article ID 854765, 5 pages, 2013.

[12] R. S. Verma, R. C. Padalia, A. Chauhan, and S. T. Thul, "Phytochemical analysis of the leaf volatile oil of walnut tree (Juglans regia L.) from western Himalaya," Industrial Crops and Products, vol. 42, no. 1, pp. 195-201, 2013.

[13] I. A. Freires, C. Denny, B. Benso, S. M. de Alencar, and P. L. Rosalen, "Antibacterial activity of essential oils and their isolated constituents against cariogenic bacteria: a systematic review," Molecules, vol. 20, no. 4, pp. 7329-7358, 2015.

[14] L. N. Barbosa, I. Da Silva Probst, B. F. M. T. Andrade et al., "In vitro antibacterial and chemical properties of essential oils including native plants from Brazil against pathogenic and resistant bacteria," Journal of Oleo Science, vol. 64, no. 3, pp. 289298, 2015. 
[15] NCCLS, Methods for Dilution Antimicrobial Susceptibility Tests for Bacteria That Grow Aerobically; Approved Standard6th Edition, NCCLS document M7-A6 (ISBN 1-56238-486-4), NCCLS, 940 West Valley Road, Suite 1400, Wayne, Pennsylvania 19087-1898 USA, 2006.

[16] D. Jesus, J. R. Oliveira, F. E. Oliveira et al., "Persea americana glycolic extract: In vitro study of antimicrobial activity against candida albicans biofilm and cytotoxicity evaluation," Scientific World Journal, vol. 2015, Article ID 531972, 5 pages, 2015.

[17] J. R. de Oliveira, R. B. de Aguiar Almeida, P. das Graças Figueiredo Vilela et al., "Control of microorganisms of oral health interest with Arctium lappa L. (burdock) extract noncytotoxic to cell culture of macrophages (RAW 264.7)," Archives of Oral Biology, vol. 59, no. 8, pp. 808-814, 2014.

[18] R. R. Watkins and R. A. Bonomo, "Antibiotic resistance in the twenty-first century: current concepts and future directions," Infectious Disease Clinics of North America, vol. 30, no. 2, pp. 13-14, 2016.

[19] The White House, The National Action Plan for Combating Antibiotic-Resistant Bacteria, The White House, Washington, DC, USA, 2015.

[20] C. E. Pleşca, M. C. Luca, A. S. Luca, S. Constantinescu, and L. S. Iancu, "Etiology and resistance profile of isolated strains from severe systemic infections in patients with immunodepression-experience of the iasi infectious diseases hospital 2011-2014," Revista Medico-Chirurgicala a Societatii de Medici si Naturalisti din Iasi, vol. 119, no. 4, pp. 1141-1146, 2015.

[21] K. J. Marwa, M. F. Mushi, E. Konje, P. E. Alele, J. Kidola, and M. M. Mirambo, "Resistance to cotrimoxazole and other antimicrobials among isolates from HIV/AIDS and Non-HIV/AIDS patients at bugando medical centre, Mwanza, Tanzania," AIDS Research and Treatment, vol. 2015, Article ID 103874, 8 pages, 2015.

[22] M. Kozłowska, A. E. Laudy, J. Przybył, M. Ziarno, and E. Majewska, "Chemical composition and antibacterial activity of some medicinal plants from Lamiaceae family," Acta Poloniae Pharmaceutica-Drug Research, vol. 72, no. 4, pp. 757-767, 2015.

[23] S. F. Van Vuuren, S. Suliman, and A. M. Viljoen, "The antimicrobial activity of four commercial essential oils in combination with conventional antimicrobials," Letters in Applied Microbiology, vol. 48, no. 4, pp. 440-446, 2009.

[24] J. A. Pereira, I. Oliveira, A. Sousa, I. C. F. R. Ferreira, A. Bento, and L. Estevinho, "Bioactive properties and chemical composition of six walnut (Juglans regia L.) cultivars," Food and Chemical Toxicology, vol. 46, no. 6, pp. 2103-2111, 2008.

[25] S. H. Abidi, K. Ahmed, S. K. Sherwani, and S. U. Kazmi, "Synergy between antibiotics and natural agents results in increased antimicrobial activity against Staphylococcus epidermidis," Journal of Infection in Developing Countries, vol. 9, no. 9, pp. 925-929, 2015.

[26] A. Farooqui, A. Khan, I. Borghetto, S. U. Kazmi, S. Rubino, and B. Paglietti, "Synergistic antimicrobial activity of Camellia sinensis and Juglans regia against multidrug-resistant bacteria," PLoS ONE, vol. 10, no. 2, Article ID e0118431, 2015.

[27] P. Matsuzaki, M. Haraguchi, G. Akisue et al., "Antineoplastic effects of butanolic residue of Pfaffia paniculata," Cancer Letters, vol. 238, no. 1, pp. 85-89, 2006.

[28] T. C. da Silva, B. Cogliati, A. O. Latorre et al., "Pfaffosidic fraction from Hebanthe paniculata induces cell cycle arrest and caspase-3-induced apoptosis in HepG2 cells," Evidence-Based Complementary and Alternative Medicine, vol. 2015, Article ID 835796, 9 pages, 2015.
[29] C. A. R. A. Costa, A. Tanimoto, A. E. V. Quaglio, L. D. Almeida, J. A. Severi, and L. C. Di Stasi, "Anti-inflammatory effects of Brazilian ginseng (Pfaffia paniculata) on TNBS-induced intestinal inflammation: Experimental evidence," International Immunopharmacology, vol. 28, no. 1, pp. 459-469, 2015.

[30] K. C. Pinello, E. D. S. M. Fonseca, G. Akisue et al., "Effects of Pfaffia paniculata (Brazilian ginseng) extract on macrophage activity," Life Sciences, vol. 78, no. 12, pp. 1287-1292, 2006.

[31] Q. D. Pham, D. Topgaard, and E. Sparr, "Cyclic and linear monoterpenes in phospholipid membranes: phase behavior, bilayer structure, and molecular dynamics," Langmuir, vol. 31, no. 40, pp. 11067-11077, 2015.

[32] Y. Shiobara, S.-S. Inoue, K. Kato et al., "A nortriterpenoid, triterpenoids and ecdysteroids from Pfaffia glomerata," Phytochemistry, vol. 32, no. 6, pp. 1527-1530, 1993.

[33] M. A. Rather, B. A. Dar, M. Y. Dar et al., "Chemical composition, antioxidant and antibacterial activities of the leaf essential oil of Juglans regia L. and its constituents," Phytomedicine, vol. 19, no. 13, pp. 1185-1190, 2012.

[34] D. Naviglio, L. Le Grottaglie, M. Vitulano, M. Trifuoggi, and M. Gallo, "Characterization of essential oil components from aromatic plants that grow wild in the 'Piana del Sele' (Salerno, Southern Italy) using gas chromatography-mass spectrometry," Natural Product Communications, vol. 10, no. 7, pp. 1293-1296, 2015.

[35] S. D. Cox, C. M. Mann, J. L. Markham et al., "The mode of antimicrobial action of the essential oil of Melaleuca alternifolia (Tea tree oil)," Journal of Applied Microbiology, vol. 88, no. 1, pp. 170-175, 2000. 

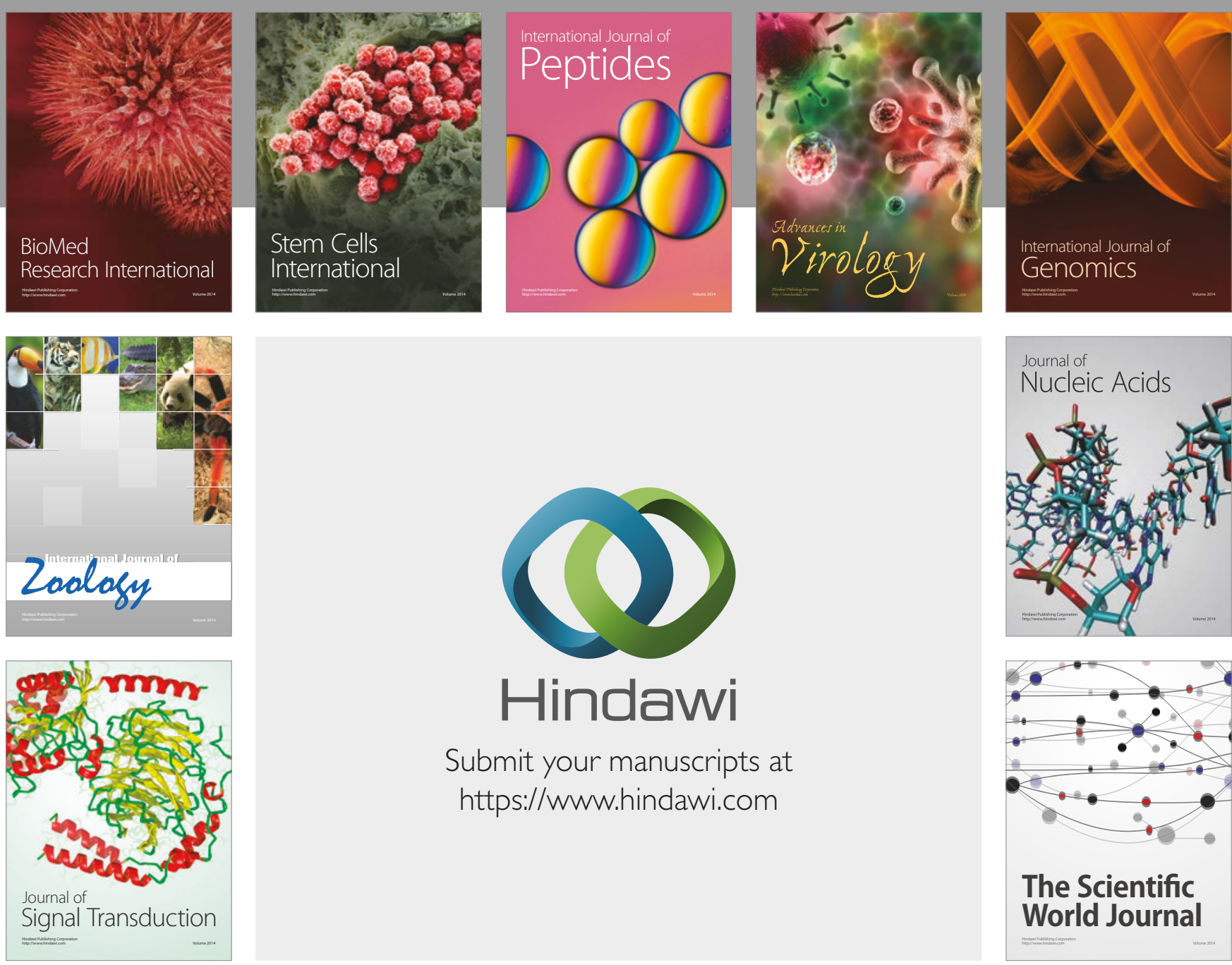

Submit your manuscripts at

https://www.hindawi.com
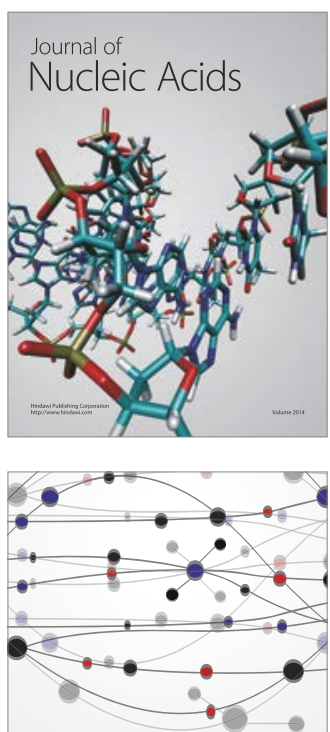

The Scientific World Journal

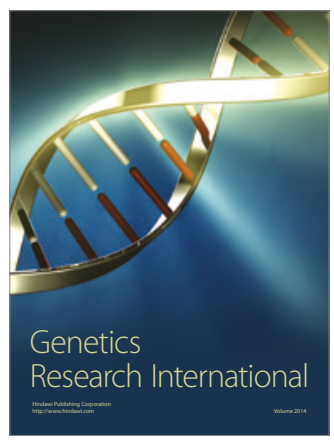

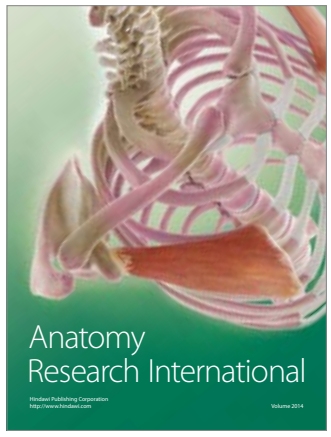

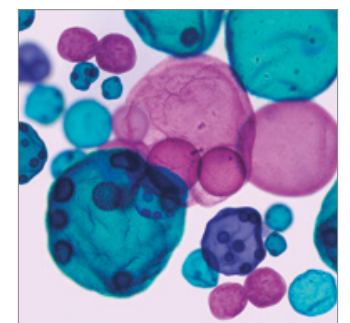

International Journal of Microbiology
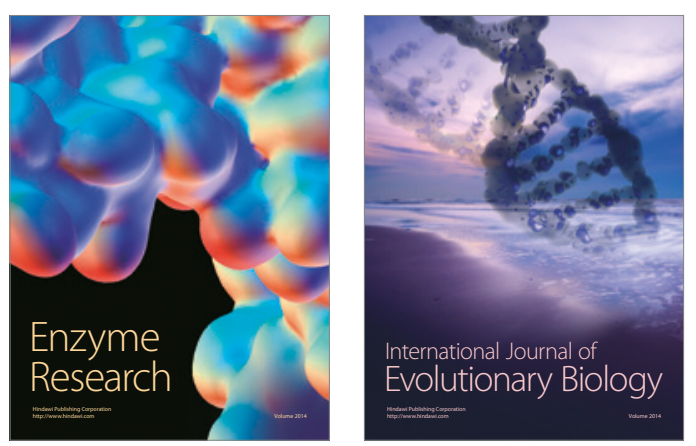
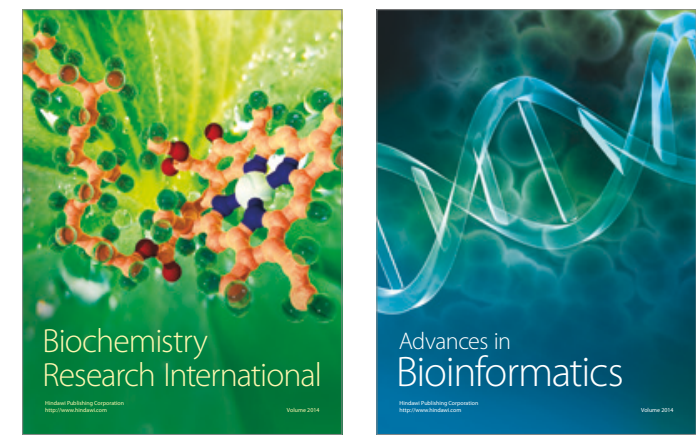

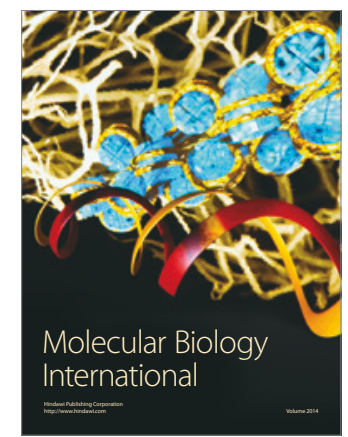

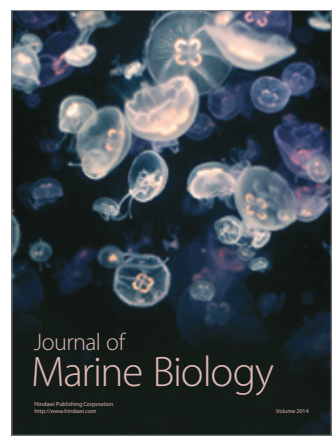

